\title{
Melting and freezing of water in cylindrical silica nanopores $\dagger$
}

\author{
S. Jähnert, ${ }^{a}$ F. Vaca Chávez, ${ }^{b}$ G. E. Schaumann, ${ }^{c}$ A. Schreiber, ${ }^{d}$ M. Schönhoff ${ }^{b}$ and \\ G. H. Findenegg $* a$
}

Received 3rd June 2008, Accepted 11th July 2008

First published as an Advance Article on the web 13th August 2008

DOI: $10.1039 /$ b809438c

Freezing and melting of $\mathrm{H}_{2} \mathrm{O}$ and $\mathrm{D}_{2} \mathrm{O}$ in the cylindrical pores of well-characterized MCM-41 silica materials (pore diameters from 2.5 to $4.4 \mathrm{~nm}$ ) was studied by differential scanning calorimetry (DSC) and ${ }^{1} \mathrm{H}$ NMR cryoporometry. Well-resolved DSC melting and freezing peaks were obtained for pore diameters down to $3.0 \mathrm{~nm}$, but not in $2.5 \mathrm{~nm}$ pores. The pore size dependence of the melting point depression $\Delta T_{\mathrm{m}}$ can be represented by the Gibbs-Thomson equation when the existence of a layer of nonfreezing water at the pore walls is taken into account. The DSC measurements also show that the hysteresis connected with the phase transition, and the melting enthalpy of water in the pores, both vanish near a pore diameter $D^{*} \approx 2.8 \mathrm{~nm}$. It is concluded that $D^{*}$ represents a lower limit for firstorder melting/freezing in the pores. The NMR spin echo measurements show that a transition from low to high mobility of water molecules takes place in all MCM-41 materials, including the one with $2.5 \mathrm{~nm}$ pores, but the transition revealed by NMR occurs at a higher temperature than indicated by the DSC melting peaks. The disagreement between the NMR and DSC transition temperatures becomes more pronounced as the pore size decreases. This is attributed to the fact that with decreasing pore size an increasing fraction of the water molecules is situated in the first and second molecular layers next to the pore wall, and these molecules have slower dynamics than the molecules in the core of the pore.

\section{Introduction}

The structure and phase behaviour of water in strongly confined systems is relevant to many fields of science and technology, ranging from geology and soil chemistry to the pharmaceutical and food preservation industries, and to a better understanding of the activity of water in biological cells. It is well-established that the hydrogen bond network of water is perturbed by the interaction with a hydrophilic substrate, and these structural changes may have a pronounced effect on the thermophysical properties of water confined in narrow pores or cavities. ${ }^{1}$ In particular, it has been found that freezing and melting of water in nanometer-sized pores occurs at temperatures much lower than in bulk. ${ }^{2-5}$ The observation that nano-confined liquid water can exist at temperatures well below its homogeneous nucleation temperature ( $c$. $235 \mathrm{~K}$ ) has prompted studies of the molecular relaxation times under these conditions, and a search for a fragile-to-strong transition in deeply supercooled confined water, ${ }^{6-8}$ as suggested by extrapolations of the anomalous thermodynamic and transport properties of bulk water to low temperatures. ${ }^{9,10}$

\footnotetext{
${ }^{a}$ Institut für Chemie, Stranski-Laboratorium, Technische Universität Berlin, Straße des 17. Juni 124, 10623 Berlin, Germany

${ }^{b}$ Institut für Physikalische Chemie, Universität Münster, Corrensstr. 30, 48149 Münster, Germany

${ }^{c}$ Institut für Integrierte Naturwissenschaften, Organische Chemie und Umweltchemie, Universität Koblenz-Landau, Universitätsstr. 1, 56072 Koblenz, Germany

${ }^{d}$ Porotec GmbH, 65719 Hofheim/Ts., Germany

$\dagger$ This article was submitted as part of a Themed Issue on water at interfaces. Other papers on this topic can be found in issue 32 of vol. 10 (2008). This issue can be found from the PCCP homepage [http://www.rsc.org/pcep].
}

Thermodynamic treatments of the solid/liquid phase transition in confined geometries ${ }^{11}$ predict a shift of the melting temperature, $\Delta T_{\mathrm{m}}$, which can be related to the pore width by the Gibbs-Thomson equation. For a pure substance in a cylindrical pore of radius $R$

$$
\Delta T_{\mathrm{m}}(R)=\frac{C_{\mathrm{GT}}}{R} \text { with } C_{\mathrm{GT}}=\frac{2 T_{0} \gamma_{\mathrm{sl}} v_{\mathrm{l}}}{\Delta h_{\mathrm{b}}}
$$

where $\gamma_{\mathrm{sl}}$ represent the surface free energy (interfacial tension) of the solid/liquid interface, $v_{1}$ is the molar volume of the liquid, and $\Delta h_{\mathrm{b}}$ the melting enthalpy in the unconfined (bulk) state, all quantities taken at the bulk coexistence temperature $T_{0}$. The values of these thermodynamic quantities for $\mathrm{H}_{2} \mathrm{O}$ and $\mathrm{D}_{2} \mathrm{O}$ water are collected in Table 1. Eqn (1) with the definition $\Delta T_{\mathrm{m}}=T_{0}-T_{\mathrm{m}}(R)$ applies to the case of complete wetting of the wall by the liquid phase, when $\gamma_{\mathrm{ws}}-\gamma_{\mathrm{wl}}=\gamma_{\mathrm{sl}}$, where $\gamma_{\mathrm{ws}}$ and $\gamma_{\mathrm{wl}}$ represent the wall-solid and wall-liquid surface free energies. The classical theories of wetting phenomena ${ }^{12}$ predict that in this case a thin liquid-like layer will intervene between the solid and the wall at and somewhat below the solid/liquid coexistence temperature. For ice against a macroscopically flat silica surface

Table 1 Thermodynamic properties of normal and heavy water in the bulk state at the normal melting temperature $T_{0}$ : melting enthalpy $\Delta h_{\mathrm{b}}$, liquid volume $v_{1}$, solid/liquid interfacial tension $\gamma_{\mathrm{sl}}$, and Gibbs-Thomson constant $C_{\mathrm{GT}}$ defined by eqn (1) (data from ref. 36, $\gamma_{\mathrm{sl}}$ from ref. 37)

\begin{tabular}{lcc}
\hline Quantity & $\mathrm{H}_{2} \mathrm{O}$ & $\mathrm{D}_{2} \mathrm{O}$ \\
\hline$T_{0} / \mathrm{K}$ & 273.15 & 276.97 \\
$\Delta h_{\mathrm{b}} / \mathrm{kJ} \mathrm{mol}^{-1}$ & 6.01 & 6.28 \\
$v_{\mathrm{l}} / \mathrm{cm}^{3} \mathrm{~mol}^{-1}$ & 18.02 & 18.12 \\
$\gamma_{\mathrm{sl}} / \mathrm{mJ} \mathrm{m}^{-2}$ & $31.7 \pm 2.7$ & $31.7 \pm 2.7$ \\
$C_{\mathrm{GT}} / \mathrm{K} \mathrm{nm}$ & $51.9 \pm 4$ & $50.7 \pm 4$ \\
\hline
\end{tabular}


it was found ${ }^{13}$ that interfacial premelting starts at a temperature $15 \mathrm{~K}$ below $T_{0}$ and that the thickness of the quasi-liquid layer strongly increases as $T_{0}$ is approached. Theoretical studies have indicated, however, that for curved substrates all wetting transitions are suppressed and, for cylinders and spheres, the prewetting transition is smeared by finite-size effects. ${ }^{14}$

The freezing and melting of water confined in mesoporous silica materials of different pore morphology and width has been studied by a variety of techniques, including calorimetry, $3,5,15-17$ NMR spectroscopy, ${ }^{2,16-20} \mathrm{X}^{-\mathrm{ray}^{4}}$ and neutron diffraction. ${ }^{21-23}$ Studies of interfacial premelting in narrow pores are rare and have been hampered by the ill-defined porosity of most substrates used in the past for such studies. In their NMR study of freezing of water in the pores of Vycor silica glass Ishizaki et al. ${ }^{20}$ observed a quasi-liquid layer already at temperatures some $30 \mathrm{~K}$ below bulk melting, which grows in thickness with temperature and leads to melting of the entire pore solid at a depressed pore melting point $T_{\mathrm{m}}(R)$. Several studies reported evidence of the existence of two different states of water in the pore space, viz., free water and bound water next to the walls, and the existence of a bound nonfreezing layer of water at silica surfaces has been reported in many studies. ${ }^{2,3,17}$ An NMR study of the bound water ${ }^{18}$ indicated that two or three layers of water molecules next to the pore wall do not exhibit true freezing, but an apparent phase transition effect was inferred from the broad distribution of correlation times. The significance of this "dead" layer for the surface and pore melting of water is not clear at present.

In a preceding paper ${ }^{3}$ differential scanning calorimetry (DSC) was used to study the freezing and melting of normal water in a series of MCM-41 and SBA-15 silicas. These materials represent 2D hexagonal arrays of cylindrical pores of uniform diameters in a range from 2 to $12 \mathrm{~nm}$. A melting point depression $\Delta T_{\mathrm{m}}$ up to $50 \mathrm{~K}$ was found, and the dependence of $\Delta T_{\mathrm{m}}$ on the pore radius $R$ could be represented within experimental error by a relation $\Delta T_{\mathrm{m}}=C /(R-t)$, with temperature independent values of the parameters $C$ and $t \approx 0.4 \mathrm{~nm}$, corresponding to 1-2 monolayers of nonfreezing water at the pore wall. These findings were in agreement with an earlier NMR cryoporometry study by Schmidt et al., ${ }^{2}$ while a recent study of Kittaka et al. ${ }^{5}$ suggests that such a relation does not apply for the full series of MCM-41 materials.

In this work we study the melting point depression and the enthalpy of melting of normal and heavy water in the pores of five MCM-41 materials. The study is focussed on a clarification of the status of the Gibbs-Thomson equation, and on the question of how crystallization as a first-order phase transition is terminated as the pore size decreases. For this reason we compare the phase transition as monitored by a thermodynamic method (DSC) with the proton NMR spinecho intensity which is a direct measure of the fraction of mobile water molecules as a function of temperature.

\section{Experimental}

\subsection{Materials}

Five MCM-41 silicas of different pore width were prepared following the prescription by Grün et al., ${ }^{24}$ using alkyltrimethylammonium bromides $\left(\mathrm{C}_{n} \mathrm{TAB}\right)$ of alkyl chain length $n=10,12,14,16$ and 18 as structure-directing templates, and tetraethoxysilane (TEOS) as the silica precursor in $25 \mathrm{wt} \%$ aqueous ammonia solution. The precipitated silica/surfactant composites were kept in the reaction solution at $35{ }^{\circ} \mathrm{C}$ under continued stirring for $2 \mathrm{~h}$, then slowly heated to $95{ }^{\circ} \mathrm{C}$ for annealing ( $72 \mathrm{~h}$ ). The materials were then filtered, washed with de-ionized water and dried at room temperature. Calcination of the materials was performed by slowly increasing the temperature $\left(1 \mathrm{~K} \mathrm{~min}^{-1}\right)$ and keeping the materials at $550{ }^{\circ} \mathrm{C}$ for $4 \mathrm{~h}$ in a stream of dry air. The calcined materials were stored in dry air until use. In the following, these materials are referred to as MCMn, where n denotes the chain length of the structure-directing surfactant.

The porosity and pore structure of the calcined materials were characterized by nitrogen adsorption ( $77 \mathrm{~K})$ and smallangle X-ray diffraction. Small-angle XRD profiles resulting from the two-dimensional hexagonal pore lattice were recorded by a MarCCD area detector using a rotating anode generator with $\mathrm{Cu} \mathrm{K} \alpha$ radiation $(\lambda=154 \mathrm{pm})$ in a range of scattering angles $(2 \theta)$ from 0.3 to $8.4^{\circ}$, corresponding to scattering vector lengths $q=(4 \pi / \lambda) \sin \theta$ from 0.2 to $6 \mathrm{~nm}^{-1}$. Small-angle XRD profiles of the present samples are shown in Fig. 1a. The lattice parameter $a_{0}$ was derived from the positions of the four leading Bragg reflexes (for MCM14 to MCM18), or from the position of the first peak (for MCM10 and MCM12). The resulting values are given in Table 2 .

Nitrogen sorption isotherms at $77.3 \mathrm{~K}$ were measured using a volumetric gas sorption system (Gemini 2375, Micromeritics Inc.). The results for the five MCM-41 samples are shown in Fig. 1b. The specific surface area $a_{\mathrm{s}}$ was determined by the BET method $^{25}$ from a pressure range $0.05<p / p_{0}<\max$, with $\max =$ 0.11 (MCM10), 0.19 (MCM12), 0.25 (MCM14), and 0.3 (MCM16, MCM18). For MCM10, the BET regime and the pore condensation regime were strongly overlapping, but the value of $a_{\mathrm{s}}$ was not changed when taking $\max =0.145$ (i.e., a pressure somewhat above the nominal pore condensation pressure) instead of $\max =0.11$, as the BET plot for this material was linear up to $p / p_{0} \approx 0.15$. The specific pore volume $v_{\mathrm{p}}$ was taken from the amount adsorbed at $p / p_{0}=0.8$ using the bulk density of liquid nitrogen at $77.3 \mathrm{~K}\left(0.8089 \mathrm{~cm}^{3} \mathrm{~g}^{-1}\right)$. For MCM10, for which the nitrogen adsorption isotherms show a high-pressure hysteresis, repeated measurements during a period of more than two years gave $v_{\mathrm{p}}$ values deviating by up to $10 \%$ from the mean value given in Table 2. For the other materials the uncertainty in $v_{\mathrm{p}}$ is estimated to be less than $5 \%$. The pore diameter was derived from the pore condensation pressure $\left(p / p_{0}\right)_{\mathrm{pc}}$ on the basis of the improved KJS prescription, ${ }^{26}$ based on the operational definition of $\left(p / p_{0}\right)_{\mathrm{pc}}$ as the pressure of maximum slope of the sorption isotherm in the pore condensation region. For MCM10 the value of $\left(p / p_{0}\right)_{\mathrm{pc}}$ cannot be determined accurately due to the overlap of the BET and pore condensation regions. The estimated value, $\left(p / p_{0}\right)_{\mathrm{pc}}=0.12 \pm 0.02$, corresponds to a pore diameter $D_{\mathrm{KJS}}=$ $2.49 \pm 0.12 \mathrm{~nm}$. The pore diameters were also determined by analysing the sorption isotherms by the non-local density functional theory (DFT), using the kernel for nitrogen in cylindrical silica pores. ${ }^{27}$ For the present materials the values of $D_{\mathrm{DFT}}$ are between 3 and $5 \%$ higher than $D_{\mathrm{KJS}}$ (see Table 2). On the other hand, the values of $D_{\mathrm{KJS}}$ are about $0.6 \mathrm{~nm}$ higher than those obtained by the conventional BJH method. ${ }^{25}$ The pore size 

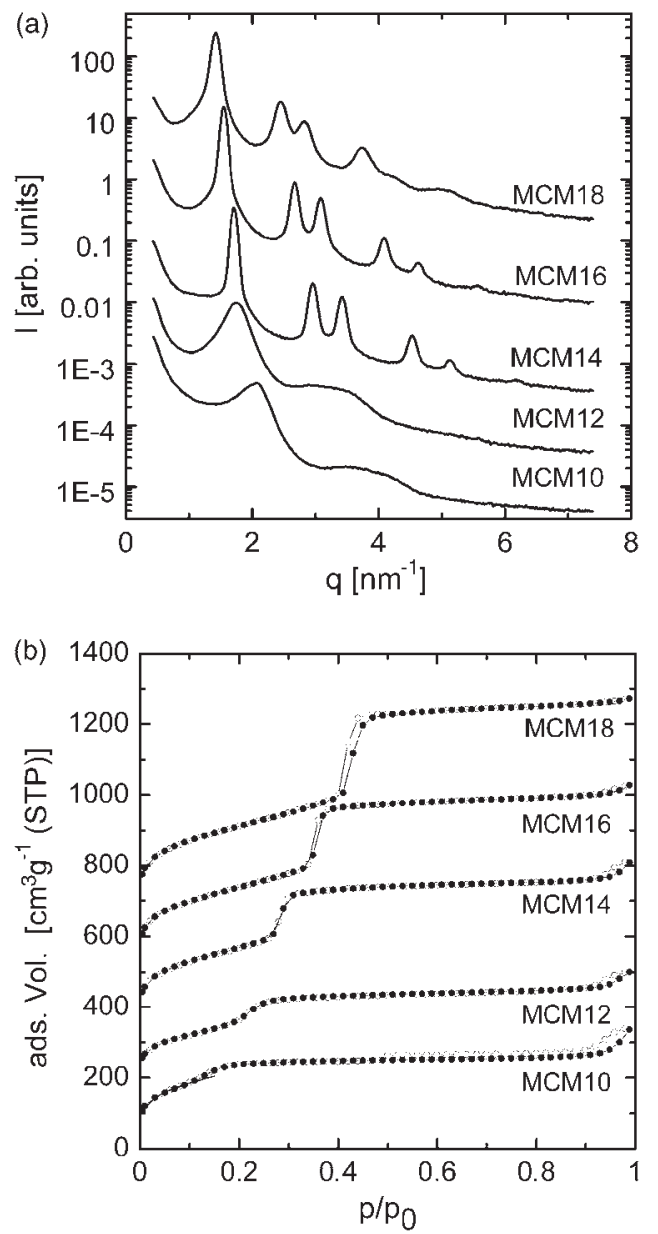

Fig. 1 Characterization of the five MCM-41 silicas: (a) small-angle powder X-ray diffraction profiles; (b) nitrogen adsorption isotherms $(77 \mathrm{~K})$ along the adsorption branch (full circles) and the desorption branch (open circles). The curves for the materials with larger pores (MCM12, etc.) are shifted relative to those with smaller pores by factors of 10 (Fig. 1a) or increments of $160 \mathrm{~cm}^{3} \mathrm{~g}^{-1}$ SPT (Fig. 1b).

distribution (psd) was determined from the DFT differential pore volume distribution as $\delta D=D_{\mathrm{a}}-D_{\mathrm{b}}$, where $D_{\mathrm{a}}$ and $D_{\mathrm{b}}$ denote the values of the pore diameter just below and above the peak in the psd (threshold value of the pore volume increment $2 \times 10^{-4}$ $\left.\mathrm{cm}^{3} \AA^{-1} \mathrm{~g}^{-1}\right)$. Values of the psd half width $\delta D / 2$ are given in Table 2.

\subsection{Methods}

Water sorption isotherms were obtained by a dynamic vapour sorption technique using a DVS Advantage instrument by
Surface Measurement Systems (London, UK). This instrument employs a Cahn D200 recording ultra-microbalance with a mass resolution of $\pm 0.1 \mu \mathrm{g}$ and a maximum load of $150 \mathrm{mg}$. The relative humidity above the sample is adjusted by mixing water-saturated and dry carrier gas streams using electronic mass flow controllers, and the desired temperature is kept constant within $\pm 0.1 \mathrm{~K}$ by enclosing the entire system in a temperature-controlled incubator. Silica samples $(\sim 20 \mathrm{mg})$ were placed into the sample pan and the standard gas flow was set to $200 \mathrm{sccm}$ (standard cubic centimetres per minute). The dry mass of the sample was taken at a relative humidity less than $0.2 \%$. The humidity was then increased in small steps and the mass increase was recorded when the mass change of the sample had become less than $0.002 \% \mathrm{~min}^{-1}$, which took up to $6 \mathrm{~h}$.

Differential scanning calorimetry measurements were made using a TA Instruments Model Q1000 DSC (TA Instruments, Alzenau, Germany) in a temperature range from 190 to $280 \mathrm{~K}$, with nitrogen as purge gas $\left(50 \mathrm{~mL} \mathrm{~min}^{-1}\right)$. Data analysis (determination of peak onset and peak maximum temperatures, and of the melting enthalpy) was performed using the Universal Analysis 2000 software by TA Instruments. Heat flow and temperature calibration was made using indium. Airdried silica samples $(0.2-2 \mathrm{mg})$ were weighed into aluminium pans and contacted with an excess of water (up to $10 \mathrm{mg}$ ). The pans were then sealed and reweighed. Well-separated DSC peaks for the freezing/melting of water in the pores and of excess water outside the pores were obtained. It was established that the position and shape of the pore melting and freezing peaks was independent of the heating/cooling rate $v$ at $v \leq 1 \mathrm{~K} \mathrm{~min}^{-1}$. The onset temperature of the melting peak of excess water was also unaffected by the heating rate at $v \leq$ $1 \mathrm{~K} \mathrm{~min}^{-1}$, while the peak maximum temperature of this peak showed some dependence on the amount of excess water and on the heating rate. All measurements reported below were performed at a heating rate of $0.5 \mathrm{~K} \mathrm{~min}^{-1}$.

NMR cryoporomerty. ${ }^{1} \mathrm{H}$ NMR cryoporometry measurements were carried out at 9.4 T on a Bruker DMX 400 spectrometer in a temperature range from 185 to $273 \mathrm{~K}$. The sample temperature was regulated and stabilized by means of a BVT 3000 Bruker temperature control unit using a flow of cold nitrogen. The temperature was calibrated by a digital Pt100 thermometer (GMH 3710), which was inserted into a $5 \mathrm{~mm}$ NMR tube filled with ethanol. The accuracy of the temperature determination is within $\pm 0.5 \mathrm{~K}$. Samples were prepared by adding $\mathrm{H}_{2} \mathrm{O}$ to the dry MCM material to fill the pores. An excess of water was present in all samples. The measurements were made according to the following protocol: the sample was cooled to $195 \mathrm{~K}$, then heated slowly $\left(1 \mathrm{~K} \mathrm{~min}^{-1}\right)$ to $265 \mathrm{~K}$ and

Table 2 Characterisation of the MCM-41 materials by nitrogen adsorption and small-angle XRD: specific surface area $a_{\mathrm{s}}$, specific pore volume $v_{\mathrm{p}}$, pore condensation pressure $\left(p / p_{0}\right)_{\mathrm{pc}}$, pore diameter $D$ (based on the KJS method and the DFT method), half-width of the pore-size distribution $\delta D / 2$, and lattice parameter $a_{0}$

\begin{tabular}{lllllll}
\hline Sample & $a_{\mathrm{s}} / \mathrm{m}^{2} \mathrm{~g}^{-1}$ & $v_{\mathrm{p}} / \mathrm{cm}^{3} \mathrm{~g}^{-1}$ & $\left(p / p_{0}\right)_{\mathrm{pc}}$ & $D_{\mathrm{KJS}} / \mathrm{nm}$ & $D_{\text {DFT }} / \mathrm{nm}$ & $\delta D / 2 / \mathrm{nm}$ \\
\hline MCM10 & 650 & 0.320 & 0.120 & 2.5 & 2.6 & 0.66 \\
MCM12 & 733 & 0.439 & 0.215 & 3.03 & 3.18 & 0.64 \\
MCM14 & 905 & 0.659 & 0.283 & 3.43 & 3.54 & 0.70 \\
MCM16 & 927 & 0.781 & 0.357 & 3.91 & 4.09 & 4.15 \\
MCM18 & 964 & 0.932 & 0.427 & 4.43 & 4.57 & 0.248 \\
\hline
\end{tabular}


cooled again to $195 \mathrm{~K}$ at a rate of $1 \mathrm{~K} \mathrm{~min}^{-1}$. This cycle was repeated and the sample was then kept at $185 \mathrm{~K}$ for $1 \mathrm{~h}$ before starting the measurement. ${ }^{1} \mathrm{H}$ NMR spectra were taken by the spin-echo $\left(90^{\circ}-\tau-180^{\circ}-\tau-\right.$ acquisition) pulse sequence, with $\tau=500 \mu \mathrm{s}$, in order to monitor only water of liquid-like mobility. At each experimental temperature the radiofrequency pulses were re-adjusted and the probe was re-tuned. The sample was then heated slowly $\left(0.1 \mathrm{~K} \mathrm{~min}^{-1}\right)$ to the next temperature chosen for data acquisition and equilibrated for 15 min before recording the ${ }^{1} \mathrm{H}$ NMR spectrum.

\section{Results}

\subsection{Water sorption isotherms}

Adsorption isotherms of water in the five MCM-41 materials are shown in Fig. 2. The isotherms exhibit an initial lowaffinity region. Pore condensation starts at a low adsorbed mass and leads to a plateau region in which the adsorbed mass shows a further weak and nearly linear increase with relative humidity. Unlike nitrogen, pore condensation and evaporation of water in these materials exhibit a pronounced $\mathrm{H} 1$ type hysteresis, ${ }^{25}$ except for the material with the most narrow pores (MCM10), in which the ascending curve is broadened and some further hysteresis occurs in the regime beyond pore condensation. Both these features indicate that MCM10 is less well-ordered than the other materials and exhibits some secondary porosity.

The relevant data on the water adsorption are summarized in Table 3. For the materials MCM12 to MCM18, the specific adsorbed mass at the onset of pore condensation, $\left(m_{\mathrm{w}} / m_{\mathrm{s}}\right)_{\mathrm{ons}}=$ $0.10 \pm 0.005 \mathrm{~g}$ water per $\mathrm{g}$ silica, corresponds to a surface density of water molecules $N_{\mathrm{w}, \text { ons }}$ of $3-4 \mathrm{~nm}^{-2}$, similar to the surface density of silanol groups in MCM-41 $\left(N_{\mathrm{OH}}=3 \mathrm{~nm}^{-2}\right)$ as determined by ${ }^{15} \mathrm{~N}$ solid-state NMR with pyridine as a probe molecule. ${ }^{28}$ Our values of $\left(m_{\mathrm{w}} / m_{\mathrm{s}}\right)_{\text {ons }}$ are similar to the value reported by Kocherbitov and Alfredsson ${ }^{29}$ for a MCM-41 sample hydroxylated under mild conditions, based on a

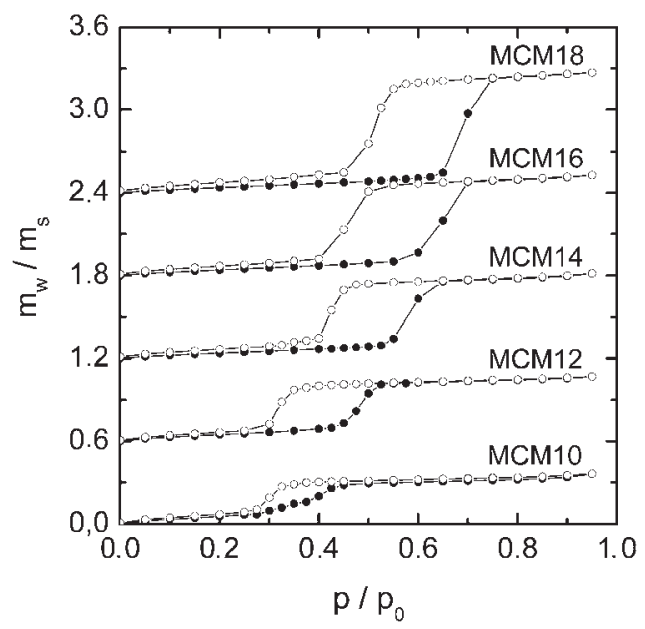

Fig. 2 Water adsorption isotherms in the five MCM-41 materials $\left(20{ }^{\circ} \mathrm{C}\right)$ plotted as adsorbed mass of $\mathrm{H}_{2} \mathrm{O}$ per unit mass of silica, $m_{\mathrm{w}} / m_{\mathrm{s}}, v s$. relative humidity $p / p_{0}$ : adsorption scan (full circles) and desorption scan (open circles). Curves for MCM12 to MCM18 are shifted upward by constant increments of $0.6 \mathrm{~g} \mathrm{~g}^{-1}$.
Table 3 Analysis of water sorption isotherms in the MCM-41 materials: pore condensation pressure $\left(p / p_{0}\right)_{\mathrm{pc}}$; specific adsorbed mass $\left(m_{\mathrm{w}} / m_{\mathrm{s}}\right)_{\text {ons }}$ and respective surface density $N_{\mathrm{w} \text {,ons }}$ of water at the onset of pore condensation; specific adsorbed mass $\left(m_{\mathrm{w}} / m_{\mathrm{s}}\right)_{\text {filled }}$ and respective number density $N_{\mathrm{w}}$ of water at complete pore filling

\begin{tabular}{llllll}
\hline Sample & $\left(p / p_{0}\right)_{\mathrm{pc}}$ & $\left(m_{\mathrm{w}} / m_{\mathrm{s}}\right)_{\mathrm{ons}}$ & $N_{\mathrm{w}, \text { ons }} / \mathrm{nm}^{-2}$ & $\left(m_{\mathrm{w}} / m_{\mathrm{s}}\right)_{\text {filled }}$ & $N_{\mathrm{w}} / \mathrm{nm}^{-3}$ \\
\hline MCM10 & 0.386 & 0.068 & 3.5 & 0.358 & 31.9 \\
MCM12 & 0.480 & 0.096 & 4.3 & 0.467 & 33.3 \\
MCM14 & 0.579 & 0.095 & 3.5 & 0.617 & 29.3 \\
MCM16 & 0.649 & 0.102 & 3.4 & 0.726 & 30.2 \\
MCM18 & 0.685 & 0.108 & 3.7 & 0.870 & 30.7 \\
\hline
\end{tabular}

sorption calorimetric study. Our values of the surface density $N_{\text {w,ons }}$ are consistent with the values obtained by an in situ solid-state NMR study of the water adsorption in MCM-41, according to which the adsorbed amount at the onset of pore condensation corresponds to about one monolayer of water molecules. $^{30}$ Apparently, the water adsorption affinity of MCM-41 is significantly lower than that on a hydrophilic ( $\mathrm{UV} / \mathrm{O}_{3}$ treated) silicon wafer, for which a thickness of about 3 molecular layers at a relative pressure $p / p_{0}=0.3$ was found by ATR infrared spectroscopy by Asay and Kim. ${ }^{31}$

The specific mass of water in the filled pores, $\left(m_{\mathrm{w}} / m_{\mathrm{s}}\right)_{\text {filled }}$, was defined operationally as the adsorbed amount at relative pressure $p / p_{0}=\left(p / p_{0}\right)_{\mathrm{pc}}+0.2$. From these values (Table 3$)$ in combination with the specific pore volumes $v_{\mathrm{p}}$ (Table 1) the mean number density of water in the pores was derived. On average, the resulting values, $N_{\mathrm{w}}=31.1 \pm 1 \mathrm{~nm}^{-3}$, are about $7 \%$ smaller than the number density of bulk water $\left(33.4 \mathrm{~nm}^{-3}\right.$ at $20{ }^{\circ} \mathrm{C}$ ), but no systematic dependence of the density on the pore width can be detected. In other studies ${ }^{29,32}$ the density of water in the pores of MCM-41 was reported to be $11-12 \%$ smaller than that of bulk water.

\subsection{Melting and freezing temperatures}

Freezing and melting of normal and heavy water in the cylindrical pores of the five MCM-41 materials was studied by DSC cooling-heating cycles with overfilled samples. Similar results were obtained for $\mathrm{H}_{2} \mathrm{O}$ and $\mathrm{D}_{2} \mathrm{O}$, except for a shift on the temperature axis by about $4 \mathrm{~K}$, due to the higher melting temperature of $\mathrm{D}_{2} \mathrm{O}$ (Table 1). The pore freezing and melting region of the thermograms for $\mathrm{D}_{2} \mathrm{O}$ is shown in Fig. 3 . Well-resolved pore melting and pore freezing peaks appear for water in MCM18 to MCM14. The respective peaks for water in MCM12 are much broader, and no pore melting and freezing peaks were detectable in the MCM10 material down to $190 \mathrm{~K}$. Repeated cooling/heating cycles gave wellreproducible peaks, indicating that the silica matrix was not damaged by the freezing of water in the pores.

The width of the pore melting peaks of $\mathrm{H}_{2} \mathrm{O}$ and $\mathrm{D}_{2} \mathrm{O}$ in the MCM-41 materials is shown in Fig. 4a, where the peak width is defined as $\delta T=T_{\max }-T_{\text {ons }}$, with $T_{\text {ons }}$ and $T_{\max }$ as the peak onset and peak maximum temperature, respectively. To find out if the width of the DSC peaks can be explained by a distribution of pore sizes in the silica materials, the pore radii $R_{\text {ons }}$ and $R_{\max }$ corresponding to $T_{\text {ons }}$ and $T_{\max }$ were calculated by the Gibbs-Thomson relation (eqn (2)), and the respective pore size increment $\delta R=R_{\max }-R_{\text {ons }}$ is plotted as a function of the pore radius in Fig. 4b. The values of $\delta R$ derived from the DSC curves 


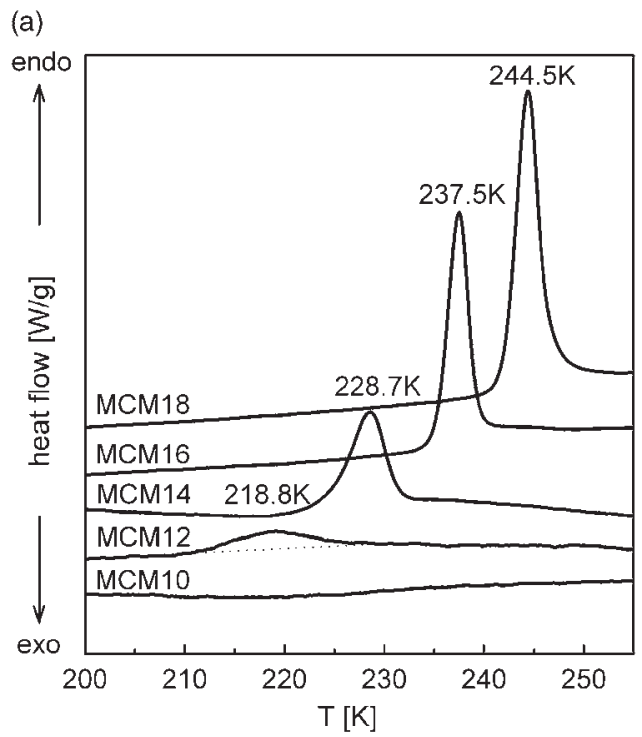

(b)

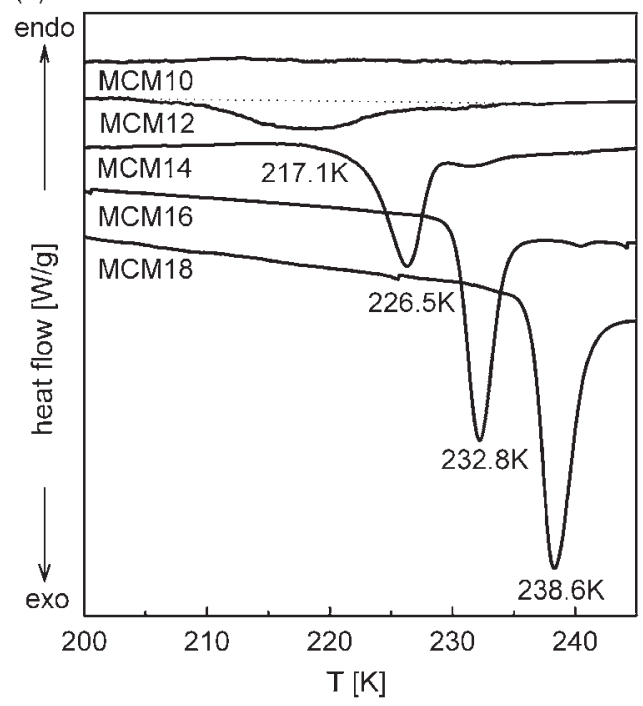

Fig. 3 DSC thermograms for pore water $\left(\mathrm{D}_{2} \mathrm{O}\right)$ in the five MCM-41 materials: (a) heating mode (pore melting peaks); (b) cooling mode (pore freezing peaks); the numbers give the peak temperatures of the respective signal. No melting or freezing peaks are detected for water in MCM10.

in this way ( 0.07 to $0.09 \mathrm{~nm}$, weakly increasing with the pore size) are similar to the half-width of the pore size distribution $\delta D / 2$ as determined from the nitrogen adsorption isotherms (Table 2). From the similar magnitude and pore size dependence of the quantities $\delta R$ and $\delta D / 2$ we conclude that the width of the DSC melting peaks is indeed caused by the (small) pore size distribution of the MCM materials. (The higher value of $\delta R$ for MCM18 obtained from the pore melting peak of $\mathrm{H}_{2} \mathrm{O}$ is attributed to experimental artifacts, since no such deviation was found in the respective pore melting peak of $\mathrm{D}_{2} \mathrm{O}$.)

Because of the effect of pore size distribution on the DSC peak width, the pore melting and freezing temperatures $T_{\mathrm{m}}$ and $T_{\mathrm{f}}$ are defined in this work by the peak maximum temperatures. Values of $T_{\mathrm{m}}$ and $T_{\mathrm{f}}$ determined in this way are given in Table 4 . These data represent mean values of 3-6
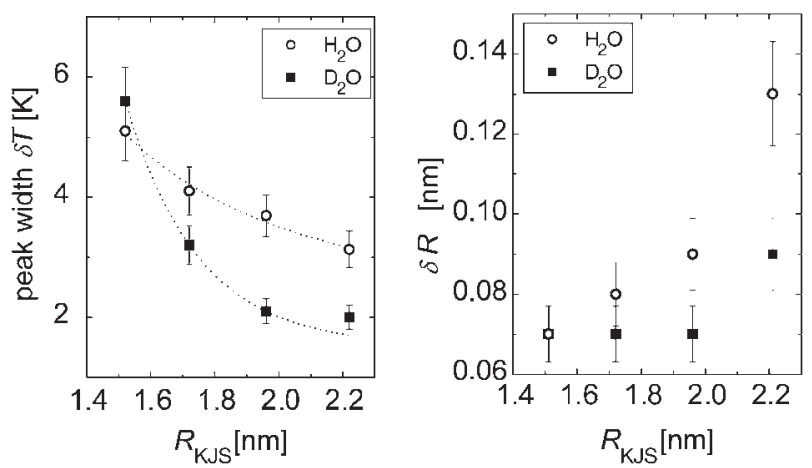

Fig. 4 (a) Half-width of the pore melting peak, $\delta T=T_{\max }-T_{\text {ons }}$, vs. pore radius $R$ for $\mathrm{H}_{2} \mathrm{O}$ and $\mathrm{D}_{2} \mathrm{O}$ in the MCM-41 materials; (b) pore size increment $\delta R$ derived from the $\delta T$ values of (a) by the GT relation. The values of $\delta R$ are to be compared with the half-width of the pore size distribution $\delta D / 2$ derived from the nitrogen adsorption isotherms (Table 2).

heating and cooling scans on two or more specimens of the respective silica materials. The present definition of $T_{\mathrm{m}}$ and $T_{\mathrm{f}}$ leads to a physically meaningful pore-size dependence of the hysteresis width $\Delta T_{\mathrm{H}}=T_{\mathrm{m}}-T_{\mathrm{f}}>0$, while a definition of $T_{\mathrm{m}}$ and $T_{\mathrm{f}}$ by the respective peak onset temperatures would lead to the unphysical result $\Delta T_{\mathrm{H}}<0$ for most samples.

The values of the melting and freezing point depression of water in the pores were determined relative to the melting peak of excess water. The onset temperature of this peak, $T_{\text {ons }}$ (bulk), was reproducible to within $\pm 0.05 \mathrm{~K}$ over all samples studied, whereas the temperature of the peak maximum showed some dependence on the chosen amount of excess water. Hence in this work the shift in the phase transition temperature of pore water is defined as $\Delta T_{\mathrm{tr}}=$ $T_{\text {ons }}$ (bulk) $-T_{\max }$ (pore). The results for the melting $\left(\Delta T_{\mathrm{m}}\right)$ and freezing $\left(\Delta T_{\mathrm{f}}\right)$ of $\mathrm{H}_{2} \mathrm{O}$ and $\mathrm{D}_{2} \mathrm{O}$ water are shown in Fig. 5 . The experimental values can be represented as a function of pore radius $R$ by a modified Gibbs-Thomson relation

$$
\Delta T_{\mathrm{tr}}=\frac{C}{R-t} .
$$

A fit of the melting and freezing data by this function is shown by the full curves in Fig. 5. Best-fit values of the parameters $C$ and $t$ for $\mathrm{H}_{2} \mathrm{O}$ and $\mathrm{D}_{2} \mathrm{O}$ are collected in Table 5. Also shown in Fig. 5 is a forced fit of the melting data with the original oneparameter GT equation, i.e., eqn (2) with $t=0$. Clearly this relation cannot reproduce the pronounced increase of $\Delta T_{\mathrm{m}}$ for pore radii below $2 \mathrm{~nm}$. The parameter $t$ is commonly interpreted as the thickness of a contact layer of nonfreezing water,

Table 4 Melting and freezing temperatures $T_{\mathrm{m}}$ and $T_{\mathrm{f}}$ of $\mathrm{H}_{2} \mathrm{O}$ and $\mathrm{D}_{2} \mathrm{O}$ water in the MCM-41 materials obtained from the DSC scans; $T_{\mathrm{fs}}$ is the maximum temperature of the satellite peaks in the cooling scans

\begin{tabular}{|c|c|c|c|c|c|c|}
\hline \multirow[b]{2}{*}{ Sample } & \multicolumn{3}{|l|}{$\underline{\mathrm{H}_{2} \mathrm{O}}$} & \multicolumn{3}{|l|}{$\mathrm{D}_{2} \mathrm{O}$} \\
\hline & $T_{\mathrm{m}} / \mathrm{K}$ & $T_{\mathrm{f}} / \mathrm{K}$ & $T_{\mathrm{fs}} / \mathrm{K}$ & $T_{\mathrm{m}} / \mathrm{K}$ & $T_{\mathrm{f}} / \mathrm{K}$ & $T_{\mathrm{fs}} / \mathrm{K}$ \\
\hline MCM12 & 215.0 & 213.1 & 215.5 & 218.8 & 217.1 & 220 \\
\hline MCM14 & 224.9 & 223.1 & 227.0 & 228.7 & 226.5 & 231.5 \\
\hline MCM16 & 233.3 & 227.8 & 236.0 & 237.5 & 232.8 & 240.5 \\
\hline MCM18 & 239.7 & 233.3 & - & 244.5 & 238.6 & - \\
\hline
\end{tabular}



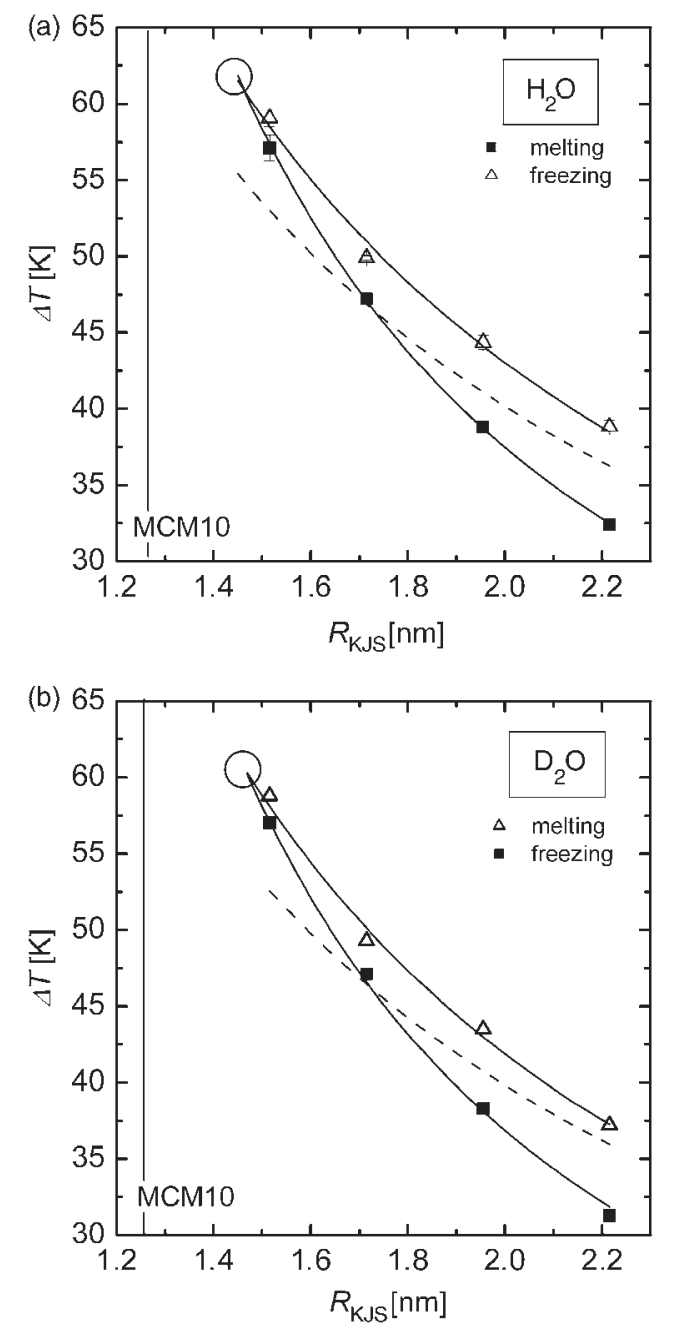

Fig. 5 Melting and freezing point depression, $\Delta T_{\mathrm{m}}$ and $\Delta T_{\mathrm{f}}$, of water in the MCM-41 materials: (a) $\mathrm{H}_{2} \mathrm{O}$; (b) $\mathrm{D}_{2} \mathrm{O}$. Full lines show a fit of the data by eqn (2), the dashed curve shows a forced fit of the $\Delta T_{\mathrm{m}}$ data with $t=0$. The point at which the hysteresis of melting/freezing disappears is indicated by a circle.

which reduces the radius of the solid core from $R$ to a value of $R-t .^{2,3,17}$

Fig. 5 shows that the width of the hysteresis $\Delta T_{\mathrm{H}}$ between the pore freezing and pore melting temperatures decreases with decreasing pore size, and the extrapolated melting and freezing lines intersect at a pore radius $R^{*}$ hys located in

Table 5 Parameters of the modified Gibbs-Thomson equation (eqn (1)) for the melting and freezing depression of $\mathrm{H}_{2} \mathrm{O}$ and $\mathrm{D}_{2} \mathrm{O}$ water in the MCM-41 materials

\begin{tabular}{llllll}
\hline & \multicolumn{3}{l}{$\mathrm{H}_{2} \mathrm{O}$} & & $\mathrm{D}_{2} \mathrm{O}$ \\
\cline { 2 - 3 } \cline { 5 - 6 } $\begin{array}{l}\text { Pore radii } \\
\text { based on }\end{array}$ & $\mathrm{KJS}$ & $\mathrm{DFT}$ & $\mathrm{KJS}$ & $\mathrm{DFT}$ \\
\hline$C / \mathrm{K} \mathrm{nm}$ & $52.4 \pm 0.6$ & $53.5 \pm 1.3$ & $50 \pm 2$ & $50 \pm 2$ \\
$t / \mathrm{nm}$ & $0.6 \pm 0.01$ & $0.66 \pm 0.03$ & $0.64 \pm 0.03$ & $0.70 \pm 0.04$ \\
$C_{\mathrm{f}} / \mathrm{K} \mathrm{nm}$ & $79 \pm 5$ & $80 \pm 4$ & $71 \pm 4$ & $73 \pm 4$ \\
$t_{\mathrm{f}} / \mathrm{nm}$ & $0.17 \pm 0.1$ & $0.24 \pm 0.1$ & $0.29 \pm 0.07$ & $0.35 \pm 0.1$ \\
$D^{*}{ }_{\text {hys }} / \mathrm{nm}$ & 2.90 & 3.02 & 2.94 & 2.92 \\
$\Delta T^{*}{ }_{\text {hys }} / \mathrm{K}$ & 61.6 & 63.0 & 60.2 & 65.8 \\
\hline
\end{tabular}

between the pore radii of MCM12 and MCM10. On the basis of eqn (2), this radius is given by

$$
R_{\mathrm{hys}}^{*}=\frac{C_{\mathrm{f}} t-C t_{\mathrm{f}}}{C_{\mathrm{f}}-C}
$$

where the parameters $C$ and $t$ refer to the melting line and the parameters $C_{\mathrm{f}}$ and $t_{\mathrm{f}}$ to the freezing line. The values of the limiting pore diameter $D^{*}{ }_{\text {hys }}=2 R^{*}{ }_{\text {hys }}$ and the respective melting point depression, $\Delta T^{*}{ }_{\text {hys }}$, for $\mathrm{H}_{2} \mathrm{O}$ and $\mathrm{D}_{2} \mathrm{O}$ are included in Table 5. The disappearance of melting/freezing hysteresis at a pore size between those of MCM12 and MCM10, together with the fact that no melting/freezing peak is detectable for water in MCM10, strongly indicates that no first-order melting/freezing transition of water occurs at pore diameters below $D_{\text {hys }} \approx 2.9 \mathrm{~nm}$. We return to this point in section 4.3.

Due to the strong pore size dependence of the phase transition temperature in the pores, the fit of the melting data by eqn (2) is sensitive to the precise values of the pore radii $R$ derived in the pore size analysis. In the present analysis, a somewhat better fit was obtained when using the pore radii determined by the KJS rather than the DFT method. The parameters $C$ and $t$ based on these two sets of pore radii in the fitting procedure are compared in Table 5. It can be seen that the values of $C$ resulting from the KJS and DFT pore radii are in close agreement (difference $0.5 \%$ ), but the value of $t$ based on the KJS pore radii is about $10 \%$ smaller than that derived from the DFT pore radii. In other words, adopting somewhat larger values of the pore radii (DFT prescription; see Table 1) leads to a somewhat higher value of $t$, such that nearly the same radius of the frozen water core, $R_{\mathrm{S}}=R-t$, results for the individual samples from the KJS and DFT prescription.

While pore melting of water gives rise to a single DSC peak, a small satellite peak is observed in the cooling scans for water in MCM12, MCM14 and MCM16 above the main pore freezing peak (see Fig. 3b). In the case of MCM12 this satellite peak overlaps with the main freezing peak. The maximum temperatures of the satellite peaks, $T_{\mathrm{f}, \mathrm{s}}$, are included in Table 4. In all cases $T_{\mathrm{f}, \mathrm{s}}$ is higher than the pore melting temperature $T_{\mathrm{m}}$, but the increment $T_{\mathrm{f}, \mathrm{s}}-T_{\mathrm{m}}$ decreases with increasing pore diameter. The peak area of the satellite peak amounts to an enthalpy change of $1-2 \mathrm{~J} \mathrm{~g}^{-1}$ for $\mathrm{H}_{2} \mathrm{O}$ and $\mathrm{D}_{2} \mathrm{O}$ in MCM12, also decreasing with increasing pore diameter. No satellite peak was found in the cooling scans for water in MCM18.

\subsection{Melting enthalpies}

The molar melting enthalpy of water in the pores, $\Delta h$, was estimated from the DSC heating curves by the relation $\Delta h=$ $\Delta H /\left(n_{\mathrm{w}}-n_{\mathrm{nf}}\right)$, where $\Delta H$ is the integral enthalpy per unit mass of silica as derived from the area of the pore melting peak, $n_{\mathrm{w}}$ is the overall amount of water in the pores per unit mass of silica (Table 3), and $n_{\mathrm{nf}}$ the respective amount of nonfreezing water in the contact layer. Hence the quantity $n_{\mathrm{w}}-n_{\mathrm{nf}}$ represents the amount of water in the core (radius $R_{\mathrm{s}}=R-t$ ) which participates in the phase transition. It can be estimated from the number density of water in the pores, $N_{\mathrm{w}}$, the pore volume 
$v_{\mathrm{p}}$, pore radius $R$ and the contact layer thickness $t$ as

$$
\Delta h=\frac{\Delta H}{\left(N_{\mathrm{w}} / N_{\mathrm{A}}\right) v_{\mathrm{p}}(1-t / R)^{2}},
$$

where $N_{\mathrm{A}}$ is the Avogadro constant. In the data analysis, a mean value of the number density of water in the pores $\left(N_{\mathrm{w}}=\right.$ $31.3 \mathrm{~nm}^{-3}$, see Table 3) was used both for $\mathrm{H}_{2} \mathrm{O}$ and $\mathrm{D}_{2} \mathrm{O}$, independent of the pore width, and the pore volumes and pore radii (KJS values) were taken from Table 2 . The results of this analysis for $\mathrm{H}_{2} \mathrm{O}$ and $\mathrm{D}_{2} \mathrm{O}$ water in the materials MCM18 to MCM12 are shown in Fig. 6, where the values of the pore melting enthalpy are normalized to the bulk melting enthalpy $\Delta h_{\mathrm{b}}$ (Table 1) and plotted against the inverse radius of the solid core, $1 / R_{\mathrm{s}}$. The results for two different assumptions concerning the non-frozen contact layer are shown, viz., $t=0$ (no contact layer) and $t=0.6 \mathrm{~nm}$ (as derived from the pore size dependence of the melting temperature on the basis of eqn (2)). Assuming that the entire amount of pore water participates in freezing and melting (i.e., $t=0$ ), a normalized melting enthalpy $\Delta h / \Delta h_{\mathrm{b}}$ of $0.3 \pm 0.03$ in the material with the widest
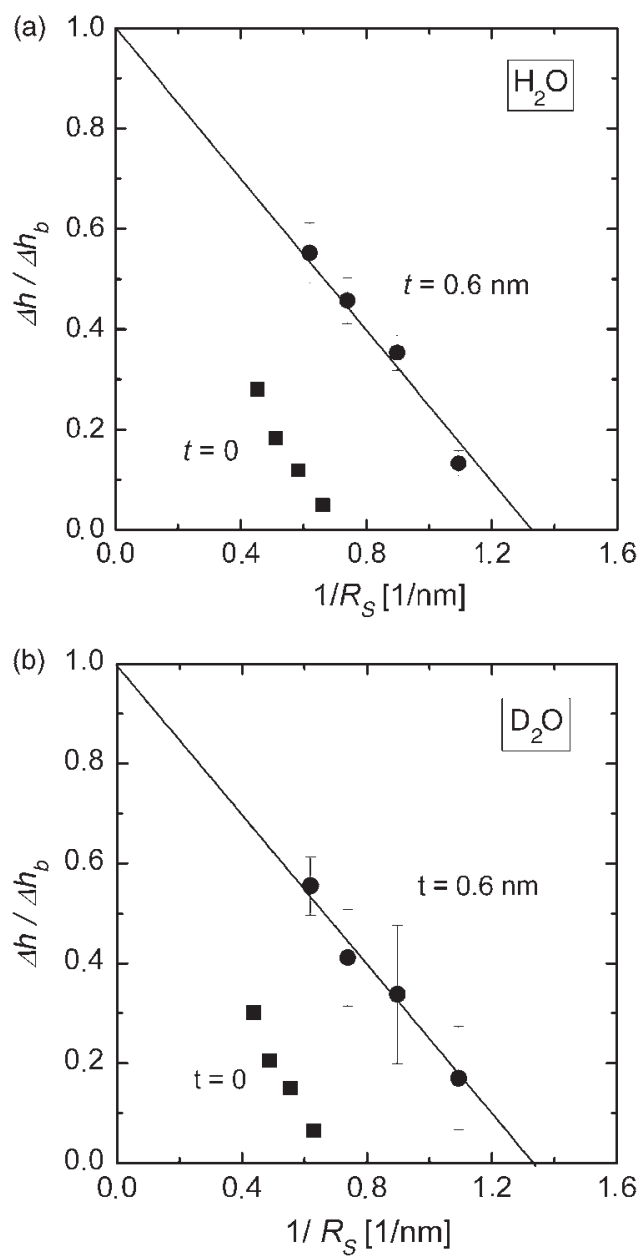

Fig. 6 Melting enthalpy $\Delta h$ of ice in the pores of MCM-41 as a function of the inverse core radius $R_{\mathrm{S}}=R-t$, for two choices of the contact layer thickness: $t=0$ (squares) and $t=0.6 \mathrm{~nm}$ (circles) for (a) $\mathrm{H}_{2} \mathrm{O}$; (b) $\mathrm{D}_{2} \mathrm{O}$. The pore melting enthalpy is normalized to the bulk melting enthalpy $\Delta h_{\mathrm{b}}$ (Table 1). The lines represent fits to the data by eqn (4). pores, and about 0.05 in the material with the most narrow pores is obtained for $\mathrm{H}_{2} \mathrm{O}$ as well as $\mathrm{D}_{2} \mathrm{O}$. Higher values of $\Delta h / \Delta h_{\mathrm{b}}$ are obtained if the existence of a nonfreezing contact layer is inferred, as in this case the measured melting enthalpy is attributed solely to the amount contained in the core of the pores. Assuming $t=0.6 \mathrm{~nm}$ yields an approximately linear dependence of $\Delta h / \Delta h_{\mathrm{b}}$ on the inverse core radius $R_{\mathrm{s}}$, which can be represented within experimental accuracy by

$$
\frac{\Delta h}{\Delta h_{\mathrm{b}}}=1-\frac{a}{R_{\mathrm{s}}}
$$

with $a=0.75 \pm 0.02 \mathrm{~nm}$. According to this relation $\Delta h / \Delta h_{\mathrm{b}}$ becomes zero at a pore radius $R_{\Delta h}^{*}=a+t$ corresponding to a diameter $D^{*}{ }_{\Delta h}=2 R^{*}{ }_{\Delta h}=2.70 \pm 0.06 \mathrm{~nm}$. The fact that a melting/freezing peak of water was observed in pores of diameter $3.0 \mathrm{~nm}$ (MCM12) but not in pores of diameter $2.5 \mathrm{~nm}$ (MCM10) is consistent with eqn (4), since the limiting pore diameter for $\Delta h / \Delta h_{\mathrm{b}}>0$ predicted by this relation is $2.70 \mathrm{~nm}$. Incidentally, if a nonfreezing layer of water is not taken into account $(t=0)$, the graph of $\Delta h / \Delta h_{\mathrm{b}} v s .1 / R_{\mathrm{s}}$ does not conform to eqn (4), as it does not extrapolate to the bulk melting enthalpy $\left(\Delta h / \Delta h_{\mathrm{b}}=1\right)$ for large pore sizes $\left(1 / R_{\mathrm{s}}=0\right)$.

\subsection{NMR cryoporometry}

The results of the proton NMR spin echo measurements of $\mathrm{H}_{2} \mathrm{O}$ in the pores of MCM10, MCM12, and MCM18 are shown in Fig. 7, where the spin echo intensity is plotted as a function of temperature in the range $190 \mathrm{~K}<T<273 \mathrm{~K}$. The intensities measured at each temperature $T$ were corrected according to Curie's law by multiplication with the factor $T / T_{\mathrm{o}}$ to account for the temperature dependence of the occupation of the spin levels under the assumption of a linearized Boltzmann distribution. The corrected intensities are normalized to the value just below $T_{\mathrm{o}}=273 \mathrm{~K}$, where all pore water is in the liquid state while all excess water (located outside the pores) is still frozen.

The smooth increase of the signal intensity with temperature in the region of pore melting indicates a transition of water in the pores. Following the model introduced by Overloop and

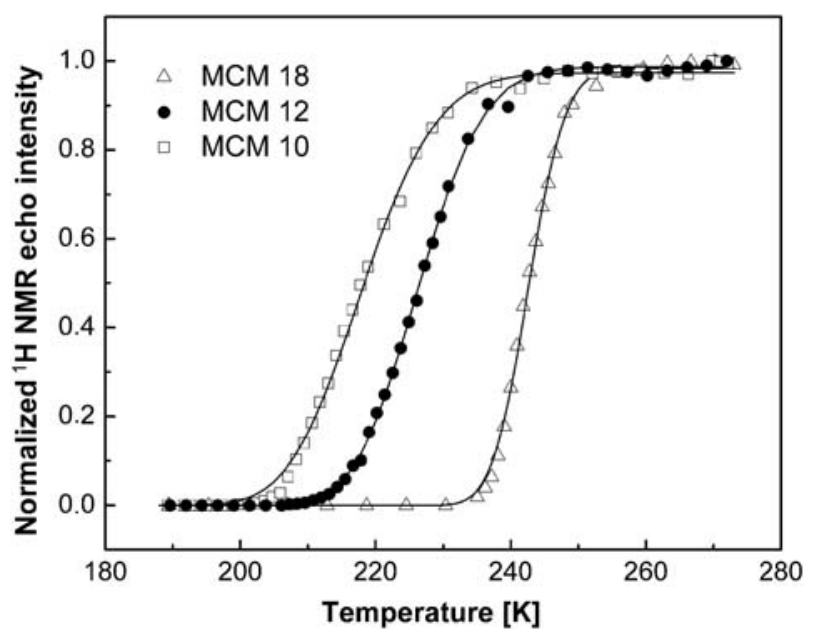

Fig. 7 Normalized proton NMR echo intensity $v s$. temperature for $\mathrm{H}_{2} \mathrm{O}$ water confined in the materials MCM10, MCM12, and MCM18. The lines show a fit of the data by eqn (6). 
Table 6 Transition temperatures, $T_{\mathrm{c}}$, and width of the melting temperature distribution curve, $\Delta$, as extracted from NMR cryoporometry

\begin{tabular}{lll}
\hline Sample & $T_{\mathrm{c}} / \mathrm{K}$ & $\Delta / 10^{5} \mathrm{~K}^{-1}$ \\
\hline MCM10 & $218 \pm 1$ & $18.3 \pm 0.3$ \\
MCM12 & $226 \pm 1$ & $14.7 \pm 0.2$ \\
MCM18 & $243 \pm 1$ & $7.3 \pm 0.1$ \\
\hline
\end{tabular}

van Gerven, ${ }^{18}$ the temperature dependence of the liquid state NMR signal can be analyzed assuming a log-normal distribution of motional correlation times of the molecules, $P(\tau)$,

$$
P(\tau)=\frac{1}{B \sqrt{\pi}} \exp \left(-\frac{Z^{2}}{B^{2}}\right), \quad Z=\ln \left(\frac{\tau}{\tau^{*}}\right)
$$

where $B$ characterizes the width of the distribution and $\tau^{*}$ is the center of the distribution. This distribution of motional correlation times represents the pore size distribution, since the model assumes a different motional correlation time for each pore size. Then, the liquid state NMR signal intensity as a function of the temperature can be expressed as ${ }^{33}$

$$
I(T)=I_{0}\left\{1+\operatorname{erf}\left[\frac{1}{\sqrt{2} \Delta}\left(\frac{1}{T_{\mathrm{c}}}-\frac{1}{T}\right)\right]\right\},
$$

where $I_{\mathrm{o}}, T_{\mathrm{c}}$ and $\Delta$ are the intensity, the transition temperature and a parameter describing the width of the melting temperature distribution curve, respectively, and $\operatorname{erf}(x)$ is the error function defined as

$$
\operatorname{erf}(x)=\frac{2}{\sqrt{\pi}} \int_{-\infty}^{x} \exp \left(-u^{2}\right) \mathrm{d} u
$$

The solid lines in Fig. 7 represent the fit of the experimental data by eqn (6). Best fit values of the parameters $T_{\mathrm{c}}$ and $\Delta$ are listed in Table 6. The quality of the fit is excellent for water in MCM12 and nearly as good in MCM18, which indicates that for pore diameters of $3 \mathrm{~nm}$ and more the data are well represented by a single pore size with a certain width of the distribution. For water in MCM10 the fit of the data by eqn (6) is not as good as for the materials with wider pores, as the onset of the transition at low temperatures is somewhat sharper than that predicted by the model. Nonetheless, the data in Fig. 7 and the values of $\Delta$ in Table 6 clearly indicate that the width of the transition strongly increases with decreasing pore diameter.

\section{Discussion}

\subsection{Comparison of DSC and NMR results}

In this work the limits of freezing and melting of water in the cylindrical nanopores of MCM-41 materials have been studied by two methods which are probing different features of this transition: DSC is sensitive to enthalpy changes resulting from changes of the local structure (average number and strength of hydrogen bonds of a molecule), while ${ }^{1} \mathrm{H}$ NMR cryoporometry detects spins with a sufficiently long relaxation time, i.e. water molecules of high (liquid-like) mobility (motional correlation time $\tau<\tau_{\mathrm{c}}$, where $\tau_{\mathrm{c}}$ is a critical motional correlation time). Fig. 8 compares the transition temperatures $T_{\mathrm{c}}$ and width of the transition obtained by NMR with the melting and freezing temperatures $T_{\mathrm{m}}$ and $T_{\mathrm{f}}$ and width of the melting region obtained by DSC. Two important results emerge from this comparison: (i) NMR cryoporometry shows that a transition of water in the pores takes place in all MCM-41 materials studied by this method, including the material of smallest pore size (MCM10, $D=2.5 \mathrm{~nm}$ ), for which no phase transition was detected by DSC. (ii) For the materials in which the transition is detected by both methods, generally $T_{\mathrm{c}}$ is higher than $T_{\mathrm{m}}$, but the temperature increment $T_{\mathrm{c}}-T_{\mathrm{m}}$ decreases with increasing pore size, from nearly $11 \mathrm{~K}$ in $\operatorname{MCM} 12(D=3.0 \mathrm{~nm})$ to only $3 \mathrm{~K}$ in MCM18 $(D=4.4 \mathrm{~nm})$. This trend suggests that $T_{\mathrm{c}}$ will become similar or equal to $T_{\mathrm{m}}$ in materials of larger pore size. Hence the observed difference between $T_{\mathrm{c}}$ and $T_{\mathrm{m}}$ is characteristic of pore diameters below about $5 \mathrm{~nm}$. Also indicated in Fig. 8 is the width of the transition region monitored by NMR (expressed as $T_{\mathrm{c}} \pm \Delta$ ) and by DSC (expressed as $T_{\mathrm{m}} \pm \delta T$ ). It can be seen that in narrow pores the NMR transition extends over a much wider range than the DSC peak. In MCM12 as well as MCM18 the NMR transition starts a few Kelvins below the thermodynamic melting temperature $T_{\mathrm{m}}$ but extends to a significantly higher temperature (25 K above $T_{\mathrm{m}}$ for MCM12, but only $10 \mathrm{~K}$ above $T_{\mathrm{m}}$ for MCM18).

The finding that ${ }^{1} \mathrm{H}$ NMR cryoporometry gives higher transition temperatures than DSC for pore diameters below $5 \mathrm{~nm}$ is remarkable, as it is well-known that the (rotational) mobility of individual molecules in the pores may already be high at temperatures well below positional melting. ${ }^{34}$ In NMR cryoporometry the delay time $\tau$ introduces a somewhat arbitrary separation of 'mobile' and 'immobile' water molecules. To determine the fraction of liquid-like molecules in a more reliable way, Hahn echo measurements at different delay times $\tau$ and an extrapolation of the echo intensity to zero $\tau$ would be necessary. As the measurements were made only at a single delay time ( $\tau=0.5 \mathrm{~ms}$ ) the NMR transition curves can give no complete picture of the transition. Nevertheless, from the fact

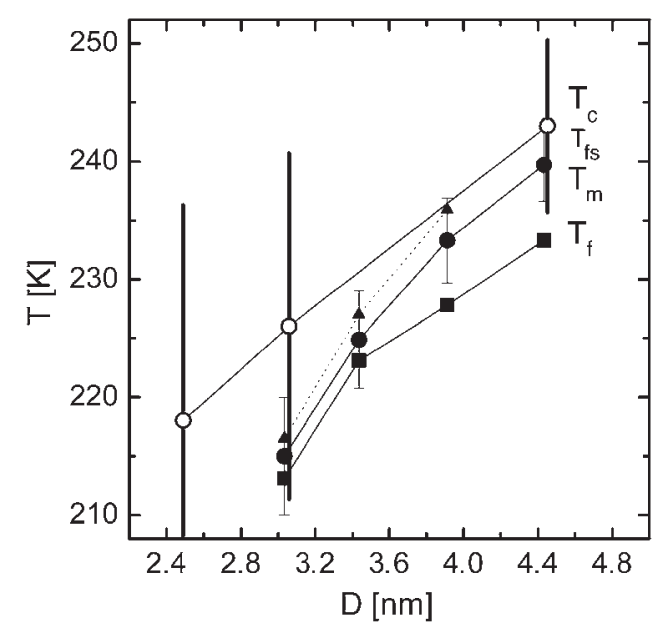

Fig. 8 Comparison of the NMR cryoporometry transition temperatures $T_{\mathrm{c}}(\bigcirc)$ with the DSC melting $(\bullet)$ and freezing ( $\left.\mathbf{\square}\right)$ temperatures and the satellite freezing peak $(\boldsymbol{\Delta})$ for $\mathrm{H}_{2} \mathrm{O}$ in the present MCM-41 materials. The vertical lines indicate the width of the NMR transition (defined as $T_{\mathrm{c}} \pm \Delta$ ) and of the DSC melting peak (defined as $T_{\mathrm{m}} \pm \delta T$ ). The lines connecting data points are drawn to guide the eye. 
that the NMR transition temperature $T_{\mathrm{c}}$ is higher than the DSC melting temperature $T_{\mathrm{m}}$ it may be speculated that at $T_{\mathrm{m}}$ part of the water molecules is still in a state of solid-like or glass-like mobility. A possible explanation for this behaviour is that molecules situated in the nonfreezing contact layer at the pore wall remain in a state of lower mobility up to temperatures above $T_{\mathrm{m}}$. If the thickness of the nonfreezing layer is independent of the pore width, as suggested by the DSC results, the fraction of molecules accommodated in this layer strongly increases with decreasing pore size. Specifically, at a layer thickness $t=0.6 \mathrm{~nm}$, the fraction of molecules in the contact layer, $\varphi=1-(1-t / R)^{2}$, increases from 47 to $73 \%$ as the pore diameter $2 R$ decreases from $4.4 \mathrm{~nm}$ (MCM18) to $2.5 \mathrm{~nm}$ (MCM10). Accordingly, at temperatures above $T_{\mathrm{m}}$ a gradient of the molecular mobility from the pore wall to the pore center may exist, gradually changing with temperature and thus leading to the observed broad distribution of transition temperatures as monitored by NMR. A similar gradient in the mobility of the molecules may also exist in narrow pores in which no true crystallization of water occurs.

The satellite peak observed in the DSC cooling scans and its pore size dependence is also indicated in Fig. 8. The significance of this small peak is not clear. A surface prefreezing effect seems most unlikely, since it would be contrary to the premelting effect of ice observed at a macroscopic ice/silica interface. ${ }^{13}$ The satellite peak might originate from some structural transition in the nonfreezing contact layer near the pore walls or, even more speculative, from a transition in the core of the pore liquid at a temperature above its freezing point. Further work is needed to elucidate the nature of this small transition.

In the next section we present arguments that the modified Gibbs-Thomson model can account for the main results obtained by DSC in pores of diameters down to $3 \mathrm{~nm}$. The limits of this description and the possible reasons for the disappearance of the DSC peaks are discussed in section 4.3. Finally, the present NMR results are compared with other NMR cryoporometry studies in section 4.4 .

\subsection{Status of the GT equation}

According to the classical GT relation a single melting temperature is attributed to each pore radius. This formalism is compatible with the existence of a nonfreezing layer at the pore walls, but not with a gradient of the melting temperature within the individual pores. Such a gradient would cause a broadening of the melting transition in the DSC scans, on top of the broadening caused by the pore size distribution. However, as explained in section 3.2, for the present systems the width of the DSC peaks can be accounted for by the pore size distribution of the MCM materials alone (Fig. 4). In particular, the broadening of the melting peaks of $\mathrm{H}_{2} \mathrm{O}$ and $\mathrm{D}_{2} \mathrm{O}$ in $\operatorname{MCM} 12(D=3 \mathrm{~nm})$ is compatible with a small pore-size distribution in this material, which is amplified by the strong pore size dependence of the melting point at these small pore widths. Hence the width of the pore melting peaks of water in the MCM materials is compatible with the concept underlying the Gibbs-Thomson relation that melting in a pore of given radius occurs at a single temperature.
Fig. 5 shows that the GT equation accounts for the melting point depression of $\mathrm{H}_{2} \mathrm{O}$ and $\mathrm{D}_{2} \mathrm{O}$ water in the pores of MCM41 down to a pore diameter $D=3.0 \mathrm{~nm}$, if one allows for the existence of a nonfreezing contact layer of water molecules at the pore walls. The existence of such a liquid-like layer at temperatures below bulk melting is to be expected on the basis of the classical wetting theory ${ }^{12}$ for the case of preferential wetting of the wall by the liquid phase. For the present case of $\mathrm{H}_{2} \mathrm{O}$ and $\mathrm{D}_{2} \mathrm{O}$ ice in silica nanopores, a layer thickness of $0.6 \mathrm{~nm}$, corresponding to about two monolayers of water molecules, is obtained by fitting eqn (2) to the pore melting temperatures. This determination of the layer thickness, $t$, is of course indirect and based on the ad-hoc assumption that the value of $t$ is independent of the pore radius. In addition, it depends on a precise knowledge of the pore diameter of the silica materials. This is illustrated by the fact that the value of $t$ derived with the present set of MCM-41 samples is greater than that reported in our earlier study $(t=0.38 \mathrm{~nm}) ;^{3}$ but this difference can be traced back to the fact that in the earlier work the pore size was determined by an empirical method which yields values of the pore diameter $D$ about $0.6 \mathrm{~nm}$ smaller than those obtained by the KJS prescription. ${ }^{35}$ As mentioned in section 3.2, changing the values of the pore radii of the set of MCM-41 materials by a certain increment causes a shift in $t$ by a similar amount, such that the values of the core radius $R_{\mathrm{s}}=R-t$ remain nearly unchanged. Although the pore size determination of the present materials is more reliable than in previous studies, the remaining uncertainty in $R$ is about $\pm 0.10 \mathrm{~nm}$, which translates into an uncertainty in $t$ of similar magnitude.

The experimental values of the parameter $C$ of eqn (2) for $\mathrm{H}_{2} \mathrm{O}$ and $\mathrm{D}_{2} \mathrm{O}$ in the MCM-41 materials (Table 5) are compatible with the thermodynamic Gibbs-Thomson constant $C_{\mathrm{GT}}$ as calculated from the established properties of water/ ice at the bulk melting temperature (Table 1), ${ }^{36,37}$ where the error bars of $C_{\mathrm{GT}}$ arise almost solely from the uncertainty in the solid/liquid interfacial free energy $\gamma_{\mathrm{sl}}$. The value of $31.7 \pm$ $2.7 \mathrm{~mJ} \mathrm{~m}^{-2}$ determined by Hillig ${ }^{37}$ is based on measurements of the undercooling needed to cause ice to grow through finepore filters of various measured pore sizes. This value agrees within the error bars with a value of $\mathrm{Hardy}^{38}$ $\left(29.1 \pm 0.8 \mathrm{~mJ} \mathrm{~m}^{-2}\right)$ obtained by measurements of the equilibrium shape of the grain boundary grooves at an ice/ water interface stabilized by an imposed temperature gradient. Both these determinations are based on the relationship between the local curvature of the ice/water interface and the ice-water coexistence temperature as described by the Gibbs-Thomson equation, but the radius of curvature was greater by one or several orders of magnitude than in the present work. It is remarkable that the Gibbs-Thomson constant derived from the present melting data in nanopores agrees within the error bars with the value based on this macroscopic value of $C_{\mathrm{GT}}$, particularly in view of the fact that the constituent thermodynamic quantities, $v_{1}, \Delta h_{\mathrm{b}}$ and (presumably) $\gamma_{\mathrm{sl}}$ are expected to show a pronounced temperature dependence in the relevant temperature range. Presumably, the apparent temperature independence of the parameter $C_{\mathrm{GT}}$ is due to a compensation of the temperature dependencies of these quantities in the Gibbs-Thomson constant $C_{\mathrm{GT}}$. Indeed, 
Turnbull $^{39}$ found a simple relationship between $\gamma_{\mathrm{sl}}$ and the heat of melting per unit area, $L$, of the form $\gamma_{\mathrm{sl}}=\lambda L$, where $\lambda$ is a constant and $L=\Delta h_{\mathrm{m}} / a_{\mathrm{m}}$, where $\Delta h_{\mathrm{m}}$ and $a_{\mathrm{m}}$ represent the melting enthalpy and the area per surface atom, respectively. Such a relation, although originally proposed in the context of the nucleation of metals, gives a good estimate of the Lennard-Jones crystal-fluid interfacial tension at the triple point, with a value $\lambda=0.32$, as was found by molecular dynamics simulations by Broughton and Gilmer. ${ }^{40}$ Adopting this value and defining the area per surface molecule as $a_{\mathrm{m}}=\left(v_{1}\right)^{2 / 3}$, as in the work of Broughton and Gilmer, we find $\gamma_{\mathrm{sl}}=33 \mathrm{~mJ} \mathrm{~m}^{-2}$ for ice/water at the bulk melting temperature, in agreement with the experimental value $\left(\gamma_{\mathrm{sl}}=31.7 \mathrm{~mJ} \mathrm{~m}^{-2}\right)$. On the basis of Turnbull's relation the GT constant can then be simplified to

$$
C_{\mathrm{GT}}=\frac{2 T_{0} \gamma_{\mathrm{sl}} v_{1}}{\Delta h_{\mathrm{sl}}}=2 \lambda T_{0} v_{1}^{1 / 3} \approx 54 \mathrm{~K} \mathrm{~nm}
$$

where $v_{1}$ now denotes the volume per molecule in the liquid and thus $v_{1}^{1 / 3}$ is a mean distance between neighbouring molecules. Hence on the basis of Turnbull's relation the temperature dependencies of the quantities of $\gamma_{\mathrm{sl}}, \Delta h_{\mathrm{b}}$, and $v_{1}$ are largely compensating each other in $C_{\mathrm{GT}}$. Although Turnbull's relation applies primarily to the triple point temperature, it is still plausible that $C_{\mathrm{GT}}$ will exhibit a much weaker temperature dependence than the constituent thermodynamic parameters.

\subsection{Limit of crystallization of water in MCM-41}

The present work confirms the findings of our earlier DSC study of $\mathrm{H}_{2} \mathrm{O}$ in MCM14, MCM16 and MCM18 that the hysteresis width of the melting/freezing transition, $\Delta T_{\mathrm{H}}$, decreases with decreasing pore diameter. ${ }^{3}$ A significant feature of pore freezing of water in these materials is the smooth and nearly symmetric shape of the freezing peaks, in contrast to the asymmetric peaks resulting from undercooled freezing of excess water, which exhibit an almost vertical rise at the onset of freezing. ${ }^{3}$ In principle, the symmetric shape of the pore freezing peaks might be due to nucleation by the ice outside the pores. In such a scenario, the observed hysteresis of pore freezing could be attributed to constrictions at the pore entrances. In this case the crystallites penetrating into the pores would have a somewhat smaller diameter than the crystallites in the interior of the pore space, which implies that nucleation will occur at a temperature below the equilibrium melting temperature in the pore. It has been suggested ${ }^{41}$ that such constrictions at the pore entrance of MCM-41 materials may result from a local Ostwald ripening effect of the silica in the presence of water. However, such a scenario cannot explain the observed systematic decrease of the hysteresis width, $\Delta T_{\mathrm{H}}$, with decreasing pore size. This behaviour is reminiscent of related phenomena in the sorption of vapours in MCM-41 and related materials, ${ }^{42,43}$ which are attributed to the proximity to criticality of the fluid in the pores (see below).

The observed pore size dependence of the melting enthalpy of water in the MCM-41 materials (section 3.3) supports the conjectured analogy of the state of ice/water with critical point phenomena of fluids in pores. Although the present data cannot prove that $\Delta h$ is truly becoming zero at some critical pore width, they show that $\Delta h$ decreases in a linear manner with the inverse core radius $1 / R_{\mathrm{s}}$ down to a pore radius of $1.5 \mathrm{~nm}$, at which $\Delta h$ amounts to only about $15 \%$ of its bulk value (Fig. 6). The extrapolation to $\Delta h=0$ yields a pore diameter $D_{\Delta h}^{*}=2.7 \pm 0.1 \mathrm{~nm}$ similar to that found for the disappearance of the hysteresis $\left(D^{*}{ }_{\text {hyst }}=2.9 \pm 0.1 \mathrm{~nm}\right)$. These findings indicate that melting and freezing as a true first-order phase transition occur only above a minimum pore diameter $D^{*}$, which is about $2.8 \mathrm{~nm}$ for MCM-41 materials. This is a higher value than that of $2.0 \mathrm{~nm}$ reported recently by Oguni et $a l .{ }^{44}$ on the basis of a calorimetric study of water in the voids of a set of silica gels. However, their determination of the limiting pore diameter was indirect (based on the pore size distribution of a silica gel of mean pore size $1.1 \mathrm{~nm}$ ) and, presumably, less accurate than our determination of $D^{*}$.

As mentioned above, the vanishing of a first-order phase transition in pores is well-established for the pore condensation of fluids in MCM-41, where the disappearance of hysteresis is commonly taken as a criterion for the criticality of the pore fluid. ${ }^{42}$ However, critical-point behaviour requires that the two phases belong to the same symmetry class, which is the case for liquid/gas, but not for solid/liquid phase coexistence. Presumably, the observed similarities in the behaviour of the present ice/water system with pore-critical phenomena of fluids in MCM-41 result from a combination of two effects: (i) increasing disorder of the ice phase as the pore size decreases; and (ii) increasing short-range order in liquid water as the temperature is lowered. It is well-established that the ice structure in the pores of MCM-41 is highly disorderd. ${ }^{4,21}$ On the other hand, the degree of local order in liquid water will increase with decreasing temperature due to local bond-ordering. ${ }^{45}$ A recent FTIR study ${ }^{46}$ of the relative populations of high-density liquid (HDL) and low-density liquid (LDL) water in narrow silica pores confirmed that while at temperatures $T>250 \mathrm{~K}$ the structure is dominated by molecules with local HDL order, at lower temperatures $(T<220 \mathrm{~K})$ the molecules of local LDL geometry are dominating. Since the local structure of LDL water resembles that of ice, the freezing process will become an increasingly cooperative phenomenon involving increasingly larger clusters of an ice-like structure, so that freezing will imply the reorganisation of hydrogen bonds only at the periphery of the clusters. ${ }^{47}$ Accordingly, as the structure of the liquid and of the solid phase will become more and more alike on a local scale, the enthalpy of freezing will decrease as the solid/liquid coexistence temperature of water in the pores is decreased. This picture is consistent with the observed narrowing of freezing/melting hysteresis as the pore size is decreased, since the activation energy for the nucleation of ice will be lowered as the degree of local bond order in the liquid increases with decreasing temperature.

\subsection{Phase transition as observed by NMR cryoporometry}

NMR cryoporometry measurements for water in a series of MCM-41 materials have been performed by Hansen and coworkers, ${ }^{2}$ who used single-pulse ${ }^{1} \mathrm{H}$ NMR experiments with a $90^{\circ}$ pulse and acquisition times of 50 or $125 \mathrm{~ms}$ to determine the intensity of the proton peak as a function of temperature. The transition temperatures obtained in this way are higher and exhibit a more pronounced pore size dependence than in 
the present work. This can be seen in Fig. 9, where the values of the pore diameter have been recalculated to conform with the KJS prescription adopted in the present work. With these somewhat higher values of the pore diameters $D$ the curve $T_{\mathrm{c}}(D)$ of Hansen et al. is shifted closer to the DSC melting curve of the present work, but still runs about $10 \mathrm{~K}$ above our $T_{\mathrm{m}}(D)$. Also shown in Fig. 9 is a cryoporometry relation $T_{\mathrm{c}}(D)$ proposed by Webber and Dore ${ }^{48}$ for the melting of water in various sol-gel silicas. These authors employed the spin echo pulse sequence as in the present work but with a delay time $\tau=2 \mathrm{~ms}$ (instead of $\tau=0.5 \mathrm{~ms}$ used in the present work). For pore diameters below $5 \mathrm{~nm}$ their relation predicts much higher values of $T_{\mathrm{c}}(D)$ (i.e., a much lower melting point depression) than in the present work and in the study of Hansen and coworkers. There are indications that the pronounced differences in the magnitude and pore size dependence of the transition temperature $T_{\mathrm{c}}(D)$ of water obtained by the spin echo method are due in part to the chosen delay time $\tau$. For instance, Webber ${ }^{49}$ studied the influence of $\tau$ on the NMR cryoporometry melting point in a $\tau$ range from 2 to $20 \mathrm{~ms}$ and found that the choice of $\tau$ is becoming very important as the pore size of the silica samples decreases. Specifically, the melting point depression of water in silica pores of nominal pore size $4 \mathrm{~nm}$ was found to be $14 \mathrm{~K}$ when measured with $\tau=$ $2 \mathrm{~ms}$, but only $6 \mathrm{~K}$ when measured with $\tau=20 \mathrm{~ms}$. This was attributed to a pore-size dependence of the relaxation time $T_{2}$ of the pore liquid. Measurements of $T_{2}$ for the present systems have not been performed as yet but may help to resolve the apparent discrepancy between the DSC and NMR results.

Hwang et al $^{50}$ performed double-quantum-filtered NMR and $T_{1}$ inversion recovery spectroscopy measurements on $\mathrm{D}_{2} \mathrm{O}$ water in MCM-41 and concluded from their results that water in MCM-41 exists at three different sites: slow motion sites (s) in the monolayer in direct contact with the silica surface; fast motion sites I $\left(f_{1}\right)$ in the second monolayer of water molecules; and fast motion sites II $\left(f_{2}\right)$ present in the third monolayer

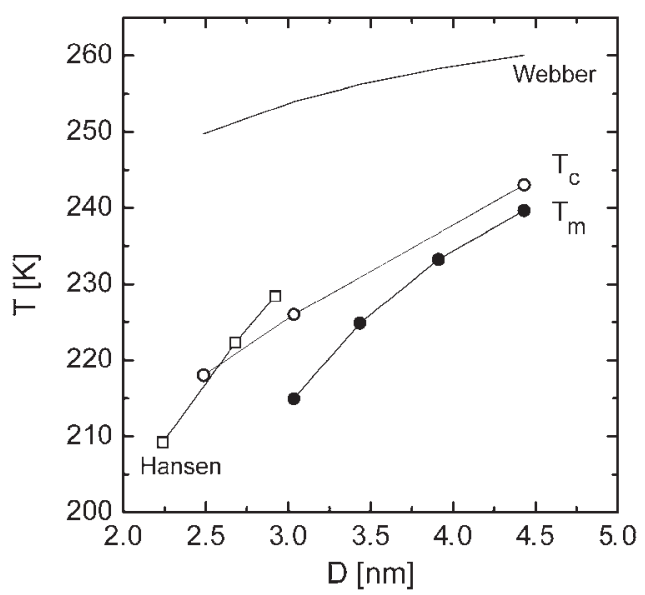

Fig. 9 Comparison of the DSC melting temperatures $T_{\mathrm{m}}(\bullet)$ with the NMR transition temperature $T_{\mathrm{c}}$ of the present work $(\bigcirc)$ and with cryoporometry data by Hansen et al. (ref. 2) for water in a different set of MCM-41 materials ( $\square$ ). The curve on top shows a NMR cryoporometry relation reported by Webber and Dore (ref. 48) for water in silica gels. above the $f_{1}$ layer. For three MCM-41 samples of nominal pore widths in the range of 2.34 to $1.58 \mathrm{~nm}$ it was found that while the motion of water molecules at slow sites exhibits little temperature dependence, water at fast motion sites exhibits a pronounced temperature dependence. Specifically, the $f_{2}$ component vanishes at temperatures from 230 to $220 \mathrm{~K}$, which is attributed to crystallization. The $f_{1}$ component exhibits a pronounced (power-law type) increase of the re-orientational correlation time which, for the sample with $2.34 \mathrm{~nm}$ pore size, occurred in a temperature range from 240 to $230 \mathrm{~K}$, i.e., above the crystallization of the core liquid.

One may speculate whether the slowing-down of the reorientation correlation time of water on fast motion sites I observed by Hwang et al. is related to the present finding of NMR spin echo transition temperatures greater than the respective DSC melting temperatures. In particular, for pore diameters just above the critical diameter $D^{*}$ this scenario could mean that on cooling the re-orientation correlation time of molecules in the core strongly increases before crystallisation, as indicated by DSC, occurs. Further NMR studies are needed to confirm this possible scenario of pore freezing. However, in view of the pronounced pore-size dependence of freezing and melting of water in these narrow pores, a proper comparison of NMR and DSC results can only be made if the same MCM-41 materials are used, as in the present study.

\section{Conclusions}

The present work was aimed at establishing the effects of pore size on the melting and freezing of water in the cylindrical pores of MCM-41. A set of well-characterized MCM-41 materials with pore diameters ranging from 2.5 to $4.4 \mathrm{~nm}$ (KJS method ${ }^{35}$ ) was used in this study. The KJS pore diameters are 0.05 to $0.15 \mathrm{~nm}$ smaller than the respective values derived by the non-local density functional theory (NLDFT), but about $0.6 \mathrm{~nm}$ greater than those obtained by the conventional $\mathrm{BJH}$ method. The study leads to the following conclusions:

(1) Water sorption isotherms in the five materials show that the amount adsorbed at the onset of pore condensation corresponds to a surface density of $3-4 \mathrm{~nm}^{-2}$, and the number density of water in the filled pores is $31 \pm 1 \mathrm{~nm}^{-3}$, i.e. about $7 \%$ lower than the bulk density at room temperature.

(2) Water exhibits nearly symmetric freezing and melting peaks in the pores of MCM-41 materials with pore diameters down to $3.0 \mathrm{~nm}$, but no melting or freezing peaks appear in the material with $2.5 \mathrm{~nm}$ pore diameter. With decreasing pore size the width of the freezing/melting hysteresis $\Delta T_{\mathrm{H}}$ shrinks and vanishes at a nominal pore diameter $D^{*}$ hys $=2.9 \mathrm{~nm}$.

(3) The melting point depression of water as a function of pore size can be represented by a modified Gibbs-Thomson relation $\Delta T_{\mathrm{m}}(R)=C /(R-t)$, where $t$ represents the thickness of a layer of nonfreezing water at the pore wall. A fit of the melting data yields $t \approx 0.6 \mathrm{~nm}$, corresponding to about two layers of water molecules. The value of the constant $C$ agrees with the Gibbs-Thomson constant $C_{\mathrm{GT}}$ as derived from the thermodynamic quantities of water/ice at the bulk coexistence temperature. Hence we conclude that the GT relation, amended by a parameter accounting for the existence of a 
nonfreezing layer, is applicable to pores down to the nanometer range.

(4) The melting enthalpy of water in the pores shows a pronounced decrease with decreasing pore size, even when taking into account that a layer next to the pore wall is not participating in the phase transition. The normalized melting enthalpy $\Delta h / \Delta h_{\mathrm{b}}$ shows a linear dependence on $1 / R_{\mathrm{s}}$, where $R_{\mathrm{s}}=R-t$, which extrapolates to $\Delta h=0$ at a pore diameter $D^{*}{ }_{\Delta h}=2.7 \mathrm{~nm}$.

(5) From the vanishing of the freezing/melting hysteresis and the vanishing of the melting enthalpy, both at a pore diameter near $2.8 \mathrm{~nm}$, it is concluded that no first-order phase transition of water occurs in MCM-41 materials below this pore size. This conclusion is supported by the fact that no pore melting/freezing peaks are observed in the material of pore diameter $2.5 \mathrm{~nm}$.

(6) Within experimental accuracy the DSC study yields the same melting/freezing behaviour of $\mathrm{H}_{2} \mathrm{O}$ and $\mathrm{D}_{2} \mathrm{O}$ in MCM41 , except for a general shift of the transition temperatures by about $4 \mathrm{~K}$, corresponding to the higher melting point of $\mathrm{D}_{2} \mathrm{O}$.

(7) NMR spin-echo measurements indicate that a transition of water takes place in all MCM-41 materials, including the material with $2.5 \mathrm{~nm}$ pore diameter, for which no phase transition was observed by DSC. The transitions monitored by NMR occur at a higher temperature and extend over a wider temperature range than the DSC peaks, particularly in narrow-sized pores.

(8) It appears that for narrow-sized pores the melting temperature of water determined on the basis of NMR spin-echo measurements depends on the chosen $\tau$. The reasons for this effect are not clear. The relation between melting temperatures obtained on the basis of spin-echo measurements (this work, Webber ${ }^{48,49}$ ) and by direct intensity measurements (Hansen $^{2}$ ) of the proton signal needs further discussion.

\section{Acknowledgements}

We thank O. Paris (MPI KG Potsdam, Germany) for SAXS measurements and M. Thommes (Quantachrome, Boynton Beach, FL, USA) for the DFT pore size analysis of our MCM41 samples. We are also indebted to S. Kittaka (Okayama University, Japan) for a discussion about the DSC satellite peaks of water in MCM-41, and to one of the referees for his comments and constructive criticism. The work at TU Berlin was supported by the Deutsche Forschungsgemeinschaft (DFG) in the framework of SFB 448 (Project B1). The work at University of Münster was funded by DFG within the German-French network 'Complex Fluids: From 3 to 2 Dimensions’ (Proposal Scho 636/3).

\section{References}

1 Recent advances in the field of water in confined geometries are presented in a special section of J. Phys.: Condens. Matter, 2004, 16(45); for a general review on the effects of confinement on freezing and melting see C. Alba-Simionesco, B. Coasne, G. Dosseh, G. Dudziak, K. E. Gubbins, R. Radhakrishnan and M. Sliwinska-Bartkowiak, J. Phys.: Condens. Matter, 2006, 18, R15.

2 R. Schmidt, E. W. Hansen, M. Stöcker, D. Akporiaye and O. H. Ellestad, J. Am. Chem. Soc., 1995, 117, 4049.
3 A. Schreiber, I. Ketelsen and G. H. Findenegg, Phys. Chem. Chem. Phys., 2001, 3, 1185.

$4 \mathrm{~K}$. Morishige and H. Iwasaki, Langmuir, 2003, 19, 2808; K. Morishige and H. Uematsu, J. Chem. Phys., 2005, 122, 044711.

5 S. Kittaka, S. Ishimaru, M. Kuranishi, T. Matsuda and T. Yamaguchi, Phys. Chem. Chem. Phys., 2006, 8, 3223.

6 M.-C. Bellissent-Funel, S. Longeville, J.-M. Zanotti and S.-H. Chen, Phys. Rev. Lett., 2000, 85, 3644.

7 A. Faraone, L. Liu, C.-Y. Mou, C.-W. Yen and S.-H. Chen, J. Chem. Phys., 2004, 121, 10843.

8 S.-H. Chen, F. Mallamace, C.-Y. Mou, M. Broccio, C. Corsaro, A. Faraone and L. Liu, Proc. Natl. Acad. Sci. U. S. A., 2006, 103, 12974.

9 R. J. Speedy and C. A. Angell, J. Chem. Phys., 1976, 65, 851.

10 P. G. Debenedetti and H. E. Stanley, Phys. Today, 2003, 56, 40; P. G. Debenedetti, J. Phys.: Condens. Matter, 2003, 15, R1669.

11 R. Evans and U. Marini Bettolo Marconi, J. Chem. Phys., 1987, 86, 7138; R. Evans, J. Phys.: Condens. Matter, 1990, 2, 8989.

12 See, for instance, J. O. Indekeu, Int. J. Mod. Phys. B, 1994, 8, 309; H. Löwen, Phys. Rep., 1994, 237, 249.

13 S. Engemann, H. Reichert, H. Dosch, J. Bilgram, V. Honkimäki and A. Snigirev, Phys. Rev. Lett., 2004, 92, 205701.

14 M. P. Gelfand and R. Lipowsky, Phys. Rev. B, 1987, 36, 8725.

15 E. Tombari, G. Salvetti, C. Ferrari and G. P. Johari, J. Chem. Phys., 2005, 122, 104712.

16 T. Takamuku, M. Yamagami, H. Wakita, Y. Masuda and T. Yamaguchi, J. Phys. Chem. B, 1997, 101, 5730.

17 E. W. Hansen, H. C. Gran and E. J. Sellevold, J. Phys. Chem. B, 1997, 101, 7027.

18 K. Overloop and L. van Gerven, J. Magn. Reson., Ser. A, 1993, 101, 179.

19 E. W. Hansen, M. Stöcker and R. Schmidt, J. Phys. Chem., 1996, 100, 2195.

20 T. Ishizaki, M. Maruyama, Y. Furukawa and J. G. Dash, J. Cryst. Growth, 1996, 163, 455.

21 J. M. Baker, J. C. Dore and P. Behrens, J. Phys. Chem. B, 1997, 101, 6226; J. C. Dore, Chem. Phys., 2000, 258, 327.

22 N. Floquet, J. P. Coulomb, N. Dufau, G. Andre and R. Kahn, Phys. B, 2004, 350, 265.

23 E. Liu, J. E. Dore, J. B. W. Webber, D. Kushalini, S. Jähnert, G. H. Findenegg and T. Hansen, J. Phys.: Condens. Matter, 2006, 18, 10009.

24 M. Grün, K. K. Unger, A. Matsumoto and K. Tsutsumi, Microporous Mesoporous Mater., 1999, 27, 207.

25 S. Lowell, J. E. Shields, M. A. Thomas and M. Thommes, Characterization of Porous Solids and Powders: Surface Area, Pore Size and Density, Kluwer Academic Publishers, Dordrecht, 2004.

26 M. Jaroniec and L. A. Solovyov, Langmuir, 2006, 22, 6757.

27 P. I. Ravikovitch and A. V. Neimark, J. Phys. Chem. B, 2001, 105, 6817.

28 I. Shenderovich, G. Buntkowsy, A. Schreiber, E. Gedat, S. Sharif, J. Albrecht, N. S. Golubev, G. H. Findenegg and H.-H. Limbach, J. Phys. Chem. B, 2003, 107, 11924.

29 V. Kocherbitov and V. Alfredsson, J. Phys. Chem. C, 2007, 111, 12906.

30 B. Grünberg, Th. Emmler, E. Gedat, I. Shenderovich, G. H. Findenegg, H.-H. Limbach and G. Buntkowsky, Chem.-Eur. J., 2004, 10, 5689; A. Vyalikh, T. Emmler, B. Grünberg, Y. Xu, I. Shenderovich, G. H. Findenegg, H.-H. Limbach and G. Buntkowsky, Z. Phys. Chem., 2007, 221, 155.

31 D. B. Asay and S. H. Kim, J. Phys. Chem. B, 2005, 109, 16760.

32 P. J. Branton, P. G. Hall, M. Treguer and K. S. W. Sing, J. Chem. Soc., Faraday Trans., 1995, 91, 2041.

33 D. Akporiaye, E. W. Hansen, R. Schmidt and M. Stöcker, J. Phys. Chem., 1994, 98, 1926.

34 E. Gedat, A. Schreiber, J. Albrecht, T. Emmler, I. Shenderovich, G. H. Findenegg, H.-H. Limbach and G. Buntkowsky, J. Phys. Chem. B, 2002, 106, 1977.

35 M. Kruk, M. Jaroniec and A. Sayari, Langmuir, 1997, 13, 6267.

36 D. Eisenberg and W. Kautzmann, The Structure and Properties of Water, Clarendon Press, Oxford, 1969.

37 W. B. Hillig, J. Cryst. Growth, 1998, 183, 463.

38 S. C. Hardy, Philos. Mag., 1977, 35, 471.

39 D. Turnbull, J. Appl. Phys., 1950, 21, 1022.

40 J. Q. Broughton and G. H. Gilmer, J. Chem. Phys., 1986, 84, 5759. 
41 A. Galarneau, M. Nader, F. Guenneau, F. Di Renzo and A. Gedeon, J. Phys. Chem. C, 2007, 111, 8268.

42 K. Morishige and M. Ito, J. Chem. Phys., 2002, 117, 8036; K. Morishige, N. Tateishi and S. Fukuma, J. Phys. Chem. B, 2003, 107, 5177; K. Morishige and M. Ishino, Langmuir, 2007, 23 11021 .

43 A. Schreiber, H. Bock, M. Schoen and G. H. Findenegg, Mol. Phys., 2002, 100, 2097.

44 M. Oguni, S. Maruyama, K. Wakabayashi and A. Nagoe, Chem.-Asian J., 2007, 2, 514.

45 H. Tanaka, J. Phys.: Condens. Matter, 2003, 15, L703.
46 F. Mallamace, M. Broccio, C. Corsaro, A. Faraone, D. Majolino, V. Venuti, L. Liu, C.-Y. Mou and S.-H. Chen, Proc. Natl. Acad. Sci. U. S. A., 2007, 104, 424; F. Mallamace, C. Branca, M. Broccio, C. Corsaro, L. Liu, C.-Y. Mou and S.-H. Chen, Proc. Natl. Acad. Sci. U. S. A., 2007, 104, 18387.

47 H. R. Pruppacher, J. Atmosph. Sci., 1995, 52, 1924.

48 B. Webber and J. Dore, J. Phys.: Condens. Matter, 2004, 16, S5449.

49 J. B. W. Webber, PhD Thesis, Canterbury, 2000.

50 D. W. Hwang, C.-C. Chu, A. K. Sinha and L.-P. Hwang, J. Chem. Phys., 2007, 126, 044702. 